\title{
STABILITY OF PLANED AND PRECISION PLANED SOLID WOOD SURFACES DUE TO WETTING
}

\author{
Zsolt Molnár ${ }^{1}$, Ingrid Fuchs ${ }^{2}$, Sándor Tatai ${ }^{1}$, Endre Magoss ${ }^{1, \star}$
}

\begin{abstract}
The upper cell layers of machined solid wood surfaces will usually be damaged and compacted due to cutting forces. The deformation zone may be instable due to temperature and moisture variations as a consequence of artificial surface treatment or environmental interaction. Therefore, an evaluation method of surface stability in this respect would be desirable.

In the frame of the new developed surface roughness evaluation method an individual wetting procedure has been developed, whilst surfaces have been characterized by 3D roughness measurement. The stability of surfaces is characterized by appropriate roughness ratios measured before and after wetting. The core depth $S$ of the Abbott parameters is the most sensitive indicator to any changes in the deformation zone. Different machining processes may produce surfaces with different stability but wood species have also definite influence on the surface stability, probably due to their density and moisture conduction properties. Latter is supported by the fact that the half-time of moisture evaporation from surfaces may differ considerably. In these experiments, planed and precision-planed surfaces were compared. According to the working principle of the precision planers the planing tool is held stationary whilst the work piece does the feeding motion, thus the blade produces a very thin slice. Using this machine, the machining roughness can be reduced to minimum as it is possible to avoid formation of cycloid arcs (like in case of traditional planing) and also possible to avoid dust formation (like in case of sanding).

Investigations were conducted on Norway spruce (Picea abies), larch (Larix decidua), scots pine (Pinus sylvestris), sessile oak (Quercus petraea), black locust (Robinia pseudoacacia), aspen (Populus tremula) and beech (Fagus sylvatica). Black locust and the sessile oak have had most stable surfaces by both machining methods. The deformation zone of precision planed surfaces has been proven to be more stable than the one of planed surfaces for all wood species.
\end{abstract}

Keywords: Cutting parameters, deformation zone, planed surface, roughness, surface stability.

\section{INTRODUCTION}

Although surface roughness can have a huge impact on finishing costs and the perceived quality of wood products, there is a lack of consensus on how to measure and evaluate wood surface roughness. Machining processes and species are the factors that significantly affect surface roughness, as opposed to the plane of section factor or the direction of the stylus tracing (Laina et al. 2017). Contact stylus surface roughness measuring method is the most common for wood surfaces. Specific recommendations are given (Gurau and Irle 2017) regarding the selection of the stylus-measuring instrument, and the

\footnotetext{
${ }^{1}$ Simonyi Károly Faculty of Engineering, Wood Science and Applied Arts, University of West Hungary, Sopron, Hungary ${ }^{2}$ Institut für Holztechnologie Dresden, gemeinnützige GmbH, Dresden, Germany

•Corresponding author: magoss.endre@uni-sopron.hu

Received: 27.10.2017 Accepted: 16.08.2018
} 
measuring conditions. The optical surface roughness measuring methods have limitations regarding the usability on wood surfaces due to errors induced by light reflections. To measure the surface roughness during the surface movement due to the wetting process, however only the optical methods are suitable thanks to their measuring speed and contactless measuring principle.

Wood changes dimension as it gains or loses moisture below the fibre saturation point. It shrinks when losing moisture from the cell walls and swells when gaining moisture in the cell walls. The speed of the shrinking or the swelling process fundamentally influences the surface structure of the wood. The shrinkage at the cellular level results from two coupled effects: cell wall properties (specially its local anisotropy) and cellular shape resulting from its formation in the cambium (Almeida et al. 2014).

Cutting of solid wood results in a thin upper layer $(5-30 \mu \mathrm{m})$ of the machined surface, usually called deformation zone (Csanády et al. 2015). This zone is created by the vertical components of the cutting forces, which compress this upper surface layer. The cell layers of this zone suffer deformation, collapse and compaction due to the cutting forces (Westkämper et al. 1997). At planing the rake angle of the tool affects the surface roughness, producing much more smooth surfaces at lower rake angles in the range of 15-25 degrees (Csanády and Magoss 2013). However, the effects of feed speed on the surface roughness were found to be negligible (Malkoçoğlu 2007). The cross section of the deformation zone is clearly identifiable on SEM images (Fischer and Schuster 1993, Gottlöber 2014), its formation can be well monitored using high frequency cameras, whilst its modelling is still an actual task.

The thickness of this deformation zone is influenced by the following major factors: the parameters of machining (tool wear, chip thickness, cutting speed etc.) and the properties of the machined wood species (MC, density, hardness, vessel diameter, tyloses, etc). In practice, it is not possible to get a machined surface without damaged cell layer even within optimal machining conditions, whilst the depth of the deformation zone has a major influence on the properties of the achieved surface. One of the most important property is the stability of the surface due to artificial treatments and environmental actions. Due to the lack of basic information on surface stability, seven wood species machined in two ways (planed and precision planed) have been investigated in order to describe their stability. The precision planing offers the smoothest machined surface, as there is no cycloid arcs due to machining, neither wood dust to fill the pores. With this machining type, the anatomical roughness is more accentuated. Water based paint systems gain advance, thus the relevance of describing the behaviour of the deformation zone during wetting becomes important.

The stability has been investigated by an individual method, developed by the authors (Molnár et al. 2015, Molnár et al. 2017). The method offers a good process monitoring during the wetting process. Preliminary we have set the frequency of data acquisition and the wetted surfaces was measured with a 3D optical surface roughness measuring instrument.

The aim of this paper are: to compare the stability of surfaces due to wetting produced with the two machining types and to rank the wood species according to their stability for the two machining types, Furthermore, to experience the suitability of the different standardized 3D roughness parameters to describe the status of the wood surface during wetting and to determine the character and measure of surface deviation by monitoring the displacements of the surface and by analysing the differences between the initial and stabilized surfaces.

\section{MATERIALS AND METHODS}

Investigations have been performed on seven wood species belonging to the most common European ones: norway spruce (Picea abies Karst.), larch (Larix decidua Mill.), scots pine (Pinus sylvestris L.), sessile oak (Quercus petraea Liebl.), black locust (Robinia pseudoacacia L.), aspen (Populus tremula L.) and beech (Fagus sylvatica L.). The selected wood species represent softwoods and hardwoods with different structural properties allowing to estimate their influence on the surface stability. From each wood species 20 samples have been taken, one batch was precision planed and 
another one planed. After surface shaping 10 samples of $100 \mathrm{~mm}$ x $100 \mathrm{~mm}$ x $12 \mathrm{~mm}$ dimension have been prepared from each wood species and from both machining types. The depth of cut of precisionplaned surfaces has been: $0,1 \mathrm{~mm}$. For investigations, all defect free, homogenous, radially cut boards have been selected. Before surface preparation, the wood material has been kept for 2 months in climate chamber at $23^{\circ} \mathrm{C}$ and $50 \%$ relative humidity. When adjusting the different machining parameters, the target was to achieve the smoothest surface possible, so the machining conditions have been set after several preliminary trials.

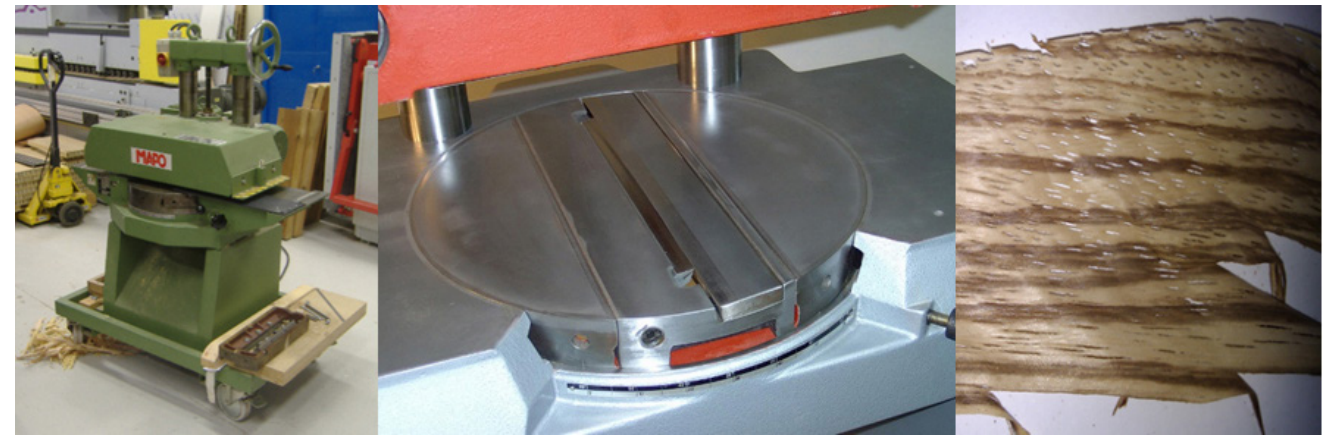

Figure 1: Precision planer, the knife setup and the special wood chip.

Precision planing has been performed with a super surfacer MAPO SPU $180 \mathrm{FH}$ type planer (Maschinenbau Pockau GmbH Germany) (Figure 1) of the Technical University of Dresden. According to the working principle of these planers, the planing tool is held stationary whilst the work piece does the feeding motion, and due to the oblique cutting mode, thus the blade may produces a very thin slice. Using this machine, the machining roughness can be reduced to minimum as it was possible to avoid formation of cycloid arcs.

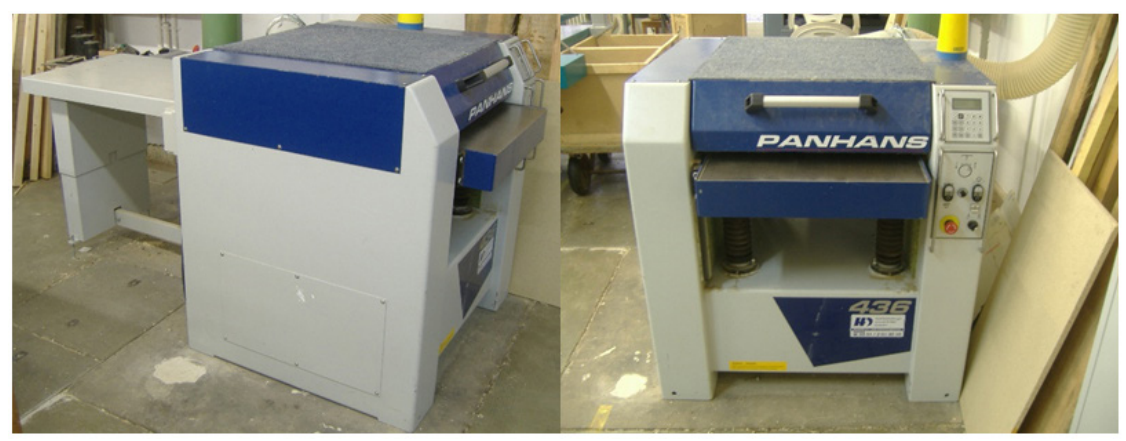

Figure 2: Planer machine.

Planing has been performed with PANHANS 436 type planer (Maschinenbau Panhans GmbH Germany) (Figure 2). The cutterhead of planer had four knives with rake angle of $20^{\circ}$ and knife angle of $50^{\circ}$. The cutting parameters used for the seven different wood species are given in Table 1. 
Table 1: Cutting parameters of planing and precision planning.

\begin{tabular}{|c|c|c|c|c|}
\hline & \multicolumn{2}{|c|}{ Precision planing } & \multicolumn{2}{c|}{ Planing } \\
\hline & $\begin{array}{c}\text { Oblique } \\
\text { angle } \\
\text { Wood species }\end{array}$ & $\begin{array}{c}\text { Feed } \\
\text { speed } \\
(\mathbf{m} / \mathbf{m i n})\end{array}$ & $\begin{array}{c}\text { Rotation } \\
\text { speed } \\
(\mathbf{1} / \mathbf{m i n})\end{array}$ & $\begin{array}{c}\text { Feed } \\
\text { speed } \\
(\mathbf{m} / \mathbf{m i n})\end{array}$ \\
\hline Spruce & 35 & 50 & 5000 & 3 \\
\hline Larch & 35 & 50 & 5000 & 3 \\
\hline Scots pine & 35 & 50 & 5000 & 3 \\
\hline Aspen & 35 & 50 & 5000 & 3 \\
\hline Sessile oak & 15 & 50 & 5000 & 3 \\
\hline Black locust & 15 & 50 & 5000 & 3 \\
\hline Beech & 15 & 50 & 5000 & 3 \\
\hline
\end{tabular}

Wetting was performed with $1 \mathrm{ml}$ distilled water, just after the manufacturing, spread on a 100 $\mathrm{mm} \times 100 \mathrm{~mm}$ surface, penetrating into the surface and simultaneously evaporating into the air. This quantity amounts the water content of a commercially available water based lacquer $\left(80-120 \mathrm{ml} / \mathrm{m}^{2}\right)$ relative to the surface area of the sample. The distilled water has been instilled drop by drop onto the surface and spread with a wet brush. The surface has been monitored by a GFMesstechnik MicroCAD type 3D optical surface roughness measuring instrument of IHD, Dresden. The measurement has been based on phase measuring fringe projection (GFMesstechnik 2008), the measured surface was 12,5 $\mathrm{mm} \times 9,5 \mathrm{~mm}$ providing 23 different $3 \mathrm{D}$ parameters $\left(\mathrm{S}_{\mathrm{a}}, \mathrm{S}_{\mathrm{q}}, \mathrm{S}_{\mathrm{k}}\right.$ etc.). On one sample, one place has been selected to monitor the behavior during wetting. The exact positioning of samples has been crucial, so a raster table, adjustable in 2 directions has been used to enable measuring exactly the same area during monitoring. Surface roughness measurements have been started after wetting when the water more or less infiltrated into the surface because free water on the surface would disturb the optical measuring system. The required waiting time was generally between 10 and 15 min depending on the half-time of evaporation.

Table 2: Frequency of measuring surface topography and number of measurements.

\begin{tabular}{|c|c|c|c|c|c|c|c|}
\hline $\begin{array}{c}\text { Time elapsed after } \\
\text { wetting (min) }\end{array}$ & $\mathrm{dry}$ & 15 & 20 & 25 & 30 & 35 & 40 \\
\hline $\begin{array}{c}\text { The number of } \\
\text { measurements }\end{array}$ & 10 & 10 & 10 & 10 & 10 & 10 & 10 \\
\hline $\begin{array}{c}\text { Time elapsed after } \\
\text { wetting (min) }\end{array}$ & 45 & 50 & 60 & 80 & 100 & 120 & 180 \\
\hline $\begin{array}{c}\text { The number of } \\
\text { measurements }\end{array}$ & 10 & 10 & 10 & 10 & 10 & 10 & 10 \\
\hline
\end{tabular}

The same area has been monitored by measuring its surface topography every 5 minutes up to 50 minutes. After one hour there were no relevant changes in the surface topography within 5 minutes, so the last 4 measurements have been performed at 80,- 100, - 120 and finally 180 minutes after wetting (Table 2). Data evaluation based on surface topography measurements has been done using ODSCAD 6.0 software (GFMesstechnik GmbH. Germany). The mass of the samples has been also measured parallel to roughness measurements, giving the evaporation of water from the surface, with an $\mathrm{MC1}$ Laboratory LC $620 \mathrm{~S}$ type balance of $0,001 \mathrm{~g}$ precision.

In order to better characterize the infiltration process we did a series of measurements on the 
same surface in the same trace, beginning after 5 minutes.

\section{D roughness parameters}

During 3D evaluation of surface roughness one single parameter cannot offer satisfactory result not even in case of metals well known for their relatively homogeneous structure (Dong et al. 1994). There are several parameters available (the measuring instrument offers 23 ), and those have been chosen which were supposed to reflect clear the changes of surface topography and express, at the same time, the direction of the variation: $S_{a}$ - average roughness, $S_{q}$ - root mean square roughness, $S_{k}$ - core roughness depth, $S_{p k}$ - reduced peak height, $S_{v k}$ - reduced valley depth, $S_{s k}-$ skewness, $S_{d r}$ - developed interfacial area ratio. The calculated roughness parameters correspond to EN ISO 2578-2:2012.

In principle, several roughness parameters will be affected by the wetting process. However, the measured core depth coincides first of all with the deformation zone due to machining and the mostly wetted upper surface layer. It is supposed; therefore, that variation in the core depth due to wetting may be an important characteristics in this case.

In order to support comparability a dimensionless number to characterize the stability of surfaces has been developed and introduced: maximal values/initial values of $S_{k}$ core depth roughness parameter (Molnár et al. 2017).

\section{RESULTS AND DISCUSSION}

$1 \mathrm{ml}$ distilled water resulted in a mass increase of around 1g (Figure 3). 20 minutes after wetting there was an appr. $0,5 \mathrm{~g}$ mass loss due to an intense evaporation of the test water. After the first half hour the evaporation process slowed down, 2-3 days are necessary for samples to reach their original mass. The calculated half-time of evaporation characterizes the infiltration depth. Water deep infiltrated evaporates more slowly requiring more time to get back to the surface.

The curves of the mass loss are almost the same for the two processing methods. The quickest mass loss was measured by the black locust samples; the slowest mass loss was measured by spruce samples. The diffusion coefficient of the black locust is lower than that of the spruce, and, therefore, less water is infiltrated into the deeper layers which resulted in a higher evaporation rate. The average intensity of evaporation from the surface can be characterized by the half-time of evaporation which is given in the Table 3. Black locust and oak have considerably shorter half-times compared to other species and this circumstance is expected to have definite influence on the surface modification after wetting.

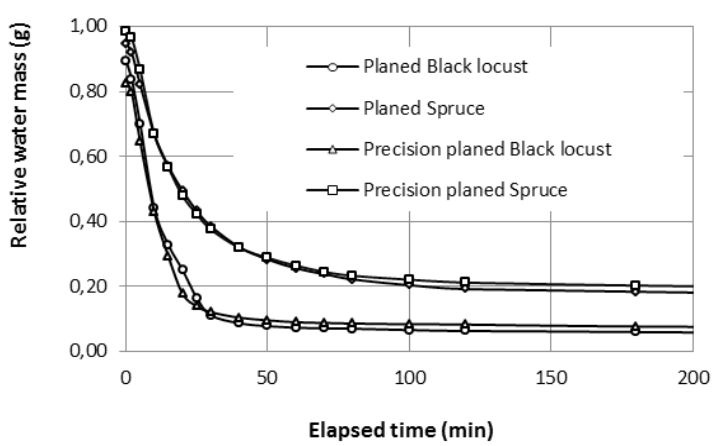

Figure 3: Changes in the relative mass of planed and precision planed black locust and spruce during evaporation.

The inherent of the planing operation is the wavy surface caused by the cycloid path (Csanády and Magoss 2013). On the other hand using the precision planer, the machining roughness can be reduced 
to minimum as it is possible by avoiding the formation of cycloid arcs (like in case of traditional planing) and dust formation (like in case of sanding). Therefore, the precision planing is used in the practice to produce smooth surfaces. In this case, the anatomical roughness will be the dominant part of the obtained surface roughness. The biasing effect of the wood anatomy caused that the initial $S_{a}$ values of the planed samples are smaller than those of the precision planed samples (Figure 4). The initial skewness $S_{s k}$ parameters have verified this explanation (Figure 5).

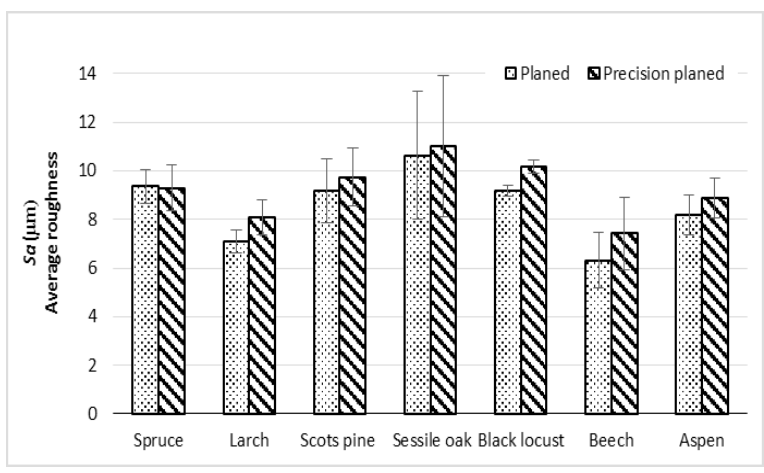

Figure 4: Initial $S_{a}$-average roughness values of planed and precision planed (not wetted) surfaces.

The ranking of the two processing methods based on the skewness values are different for softwoods and for the hardwoods. The softwood wood species less amount of holes than the hardwoods showing higher skewness values on the planed samples and the sequence of the $S_{s k}$ values is reversed for the hardwood samples. The $S_{s k}$ value is positive only by the planed beech samples.

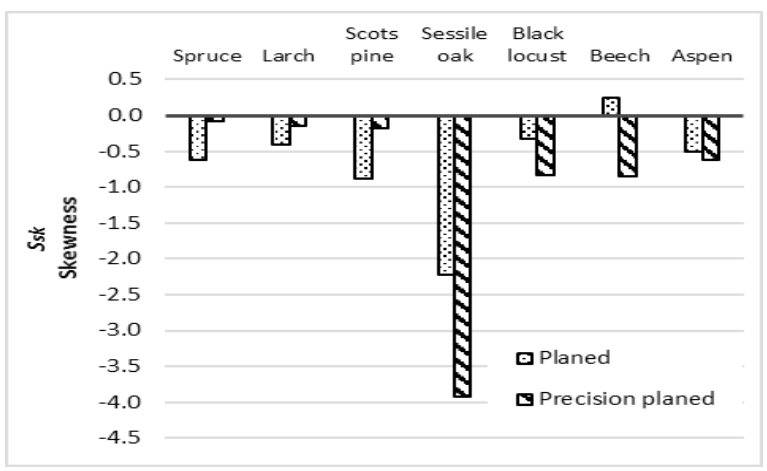

Figure 5: Initial $S_{s k}-$ skewness values for planed and precision-planed (not wetted) surfaces.

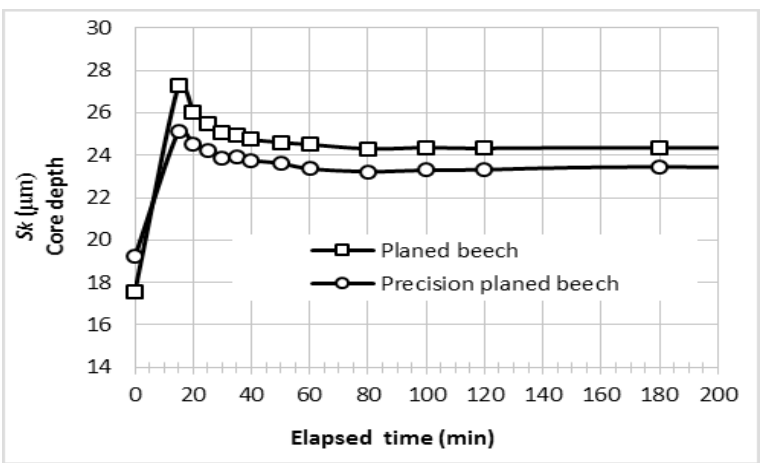

Figure 6: Variation of $S_{k}$ core depth roughness parameter of planed and precision-planed surfaces after wetting. 


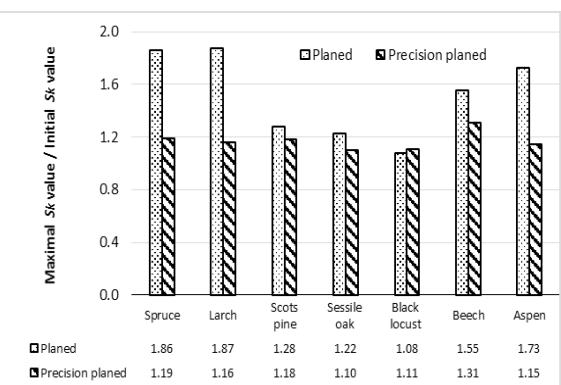

Figure 7: Maximal values/initial values of $S_{k}$ core depth roughness parameter for different wood species.

After wetting, the roughness parameters always exceed their initial values and kind of machining influences the difference between end and initial values, Figure 6 . The course of the curves shown in Figure 6 are always similar but the numerical value of difference is different. Because the surface layer deformation and the zone of water infiltration coincide much more with the measured core depth, $S_{k}$ or $R_{k}$, therefore, the relative core depth defined as the ratio of its value after wetting divided by the initial value appeared to be the best for characterization of surface stability due to wetting. The measured relative core depth values for the investigated wood species are summarized in Figure 7.

For all species, it has been proven that the deformation zone of precision-planed surfaces is more stable than that of planed samples. The measure of instability is strongly wood-species dependent. The oak, and black locust samples had the most stabile surfaces for both processing methods following by the scotch pine. The $S_{s k}$ parameter has shown that the oak, and black locust samples much less tend to grain raising (Figure 8 ) after the wetting process. It should, however, be noted that our scotch pine samples had high density around $650 \mathrm{~kg} / \mathrm{m}^{3}$.

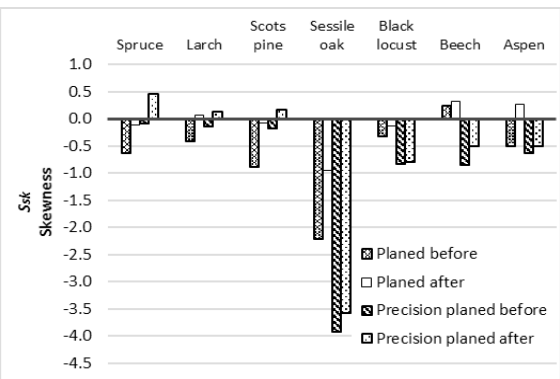

Figure 8: Values of $S s_{k}$ skewness parameter of planed and precision-planed surfaces after wetting.

The diffuse porous species beech and aspen manifested the highest instability. The highest stability has been measured in case of large porous species: black locust and oak. The reason is supposed to be that the large porous species contain lower amount of parenchyma cells. These cells possess thin primary cell walls which easily collapse during machining and are sensitive to swelling. The diffusion coefficient and the water infiltration rate play also an important role (Figure 3 and Table 3).

Table 3: Half-times of evaporation from sample surface.

\begin{tabular}{|l|c|}
\hline \multicolumn{1}{|c|}{ Wood species } & $\Delta \mathbf{t}, \mathbf{m i n}$ \\
\hline Spruce & 20 \\
\hline Larch & 18 \\
\hline Scotch pine & 22 \\
\hline Black locust & 11 \\
\hline Oak & 13 \\
\hline Beech & 19 \\
\hline Aspen & 19 \\
\hline
\end{tabular}


Infiltrating of water into the wood tissue starts immediately after wetting. The process is the most intensive and most changes occur in the deformation zone in the early phase. In order to insight into the infiltration process and its effect on the dynamics of roughness variation, some early measurements were also carried out beginning after 6 min of wetting and in one minute intervals. Measurements on oak (Quercus_petraea) sample are demonstrated in Figure 9 and Figure 10. Oak (Quercus_petraea) having big vessels behaves especially interesting because the vessels, due to swelling, become smaller in the first period. After 10 to 12 min which corresponds to the half-time of evaporation, the process turns back and the shrinkage will again open the vessels. This process can first of all be followed by the course of reduced valley depth $S_{v k}$ in both Figures.

Three roughness parameters have been calculated for one single measurement sequence on all surfaces: $S_{p k}$ - reduced peak height, $S_{k}$ - core roughness depth, and $S_{v k}$ - reduced valley depth. They reach their maximum in different time: first $S_{p k}$, than $S_{k}$ and finally $S_{v k}$. An interesting comparison can be made in the course of the core depth $S_{k}$ in Figure 9 and Figure 10. The planed oak (Quercus petraea) surface having some crashed layer shows also decrease in $S_{k}$ in contrast to the more clean surface of precision planing.

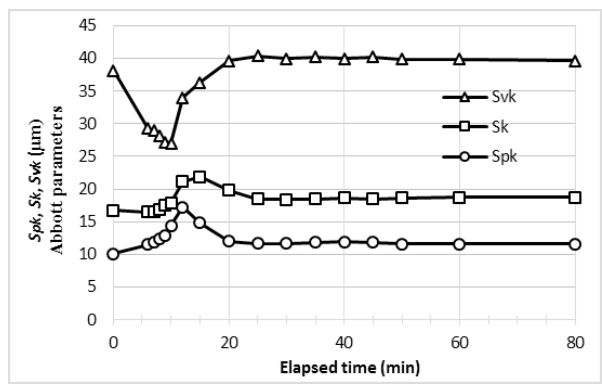

Figure 9: The course of $S_{k}, S_{p k}, S_{v k}$ in the same trace during wetting on precision planed oak surface.

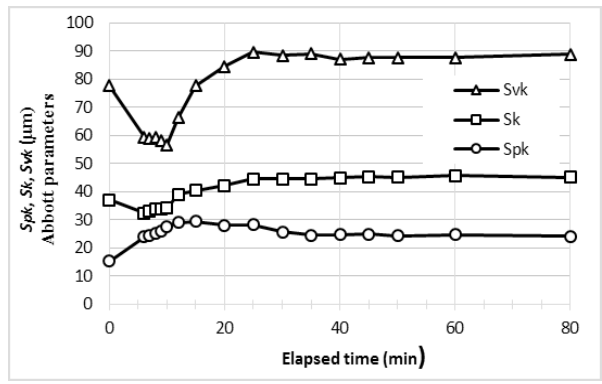

Figure 10: Trend of $S_{k}, S_{p k}, S_{v k}$ in the same trace during wetting on planed oak surface.

There are no relevant changes in the process after the first 30 minutes. The initial values and the 80 minute values of the three parameters are stabilized (we couldn't observe statistically significant difference based on Student test, $\mathrm{p}=0,05) . S_{k}$ well reflects the roughness of the core. In case of oak $S_{v k}$ was higher than $S_{p k}$, reflecting the presence of large open pores. In case of black locust there was no significant difference between its $S_{v k}$ and $S_{p k}$, reflecting that the large pores are filled with tylosis. $S_{k}$ showed that black locust is the most stable during wetting among the investigated wood species.

$S_{s k}$-skewness expresses the slope of surfaces, their asymmetry relative to the mean line. A negative parameter means a surface having numerous deep valleys, like the large porous species. Positive values are characteristic to those surfaces where the deep valleys are missing but the surface develops numerous peaks. 


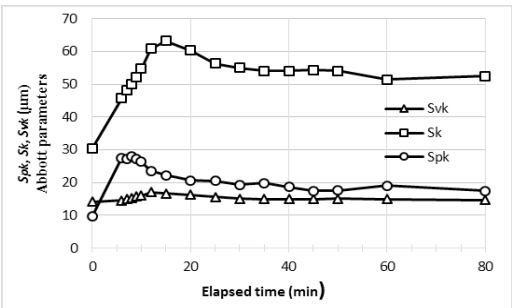

Figure 11: Trend of $S_{k}, S_{p k}, S_{v k}$ in the same trace during wetting on planed surface.

The samples, which did not contain large vessels the trend of $S_{k}, S_{p k}, S_{v k}$ parameters in the same trace during wetting process is slightly different. The larch shows the typical trend of this subclass (Figure 11). The initial value of the $S_{v k}$ parameter is smaller than the oak and the first stage has been already ascending. The stabilized $S_{v k}$ value slightly bigger than the initial value. The $S_{p k}$ and $S_{v k}$ value have shown also ascending trend in the first stage but the angle of the elevation is bigger. The alteration of these roughness parameters have shown also a maximum point.

\section{CONCLUSIONS}

Water based paint systems gain advance, thus grows the relevance of describing the behavior of the deformation zone manifested during wetting. This research targeted the description of the behavior of precision planed and planed surfaces after wetted with water, since the roughness developed during wetting might be associated with the deformation of the surface treated with coating material (paint/ adhesive) (Csiha and Gurau 2011).

Based on the experimental results the following main conclusion may be drawn:

The wetting of the surface is associated with subsequent swelling and shrinkage with residual deformation increasing the initial surface roughness.

The increase in surface roughness may be characterized to be the more sensitive to any change in the surface deformation zone.

The increase in surface roughness after wetting is determined by the anatomical structure and properties of wood species and the dynamics of moisture movement in the surface layer.

The moisture movement in the surface is governed, first of all, by the diffusion coefficient and the machining itself has much less influence. This is due to the fact that the depth of deformation made by the knife edge is around $20 \mu \mathrm{m}$ while the depth of infiltration is $1-2 \mathrm{~mm}$.

A perfectly cut surface less initiates residual deformation and, therefore, shows less increase in roughness after wetting.

For all species has been proven that the deformation zone of precision-planed surfaces is more stable than that of planed samples.

The diffuse porous species (beech and aspen) manifested the highest instability. The highest stability has been measured in case of large porous species: black locust and oak.

In case of black locust there was no significant difference between its $S_{v k}$ and $S_{p k}$, reflecting that the large pores are filled with tylosis. $S_{k}$ showed that black locust is the most stable during wetting among the investigated wood species.

\section{ACKNOWLEDGEMENTS}

The authors would like to acknowledge the Human Resource Development Programme (HRDOP 3.6.1-16-2016-00018) "Improving the role of research+development+innovation in the higher education through institutional developments assisting intelligent specialization in Sopron and Szombathely"at 
University of West Hungary for financially supporting this work.

\section{REFERENCES}

Almeida, G.; Huber, F.; Perré, P. 2014. Free shrinkage of wood determined at the cellular level using an enviromental scanning electron microscope. Maderas-Cienc Tecnol 16(2): 187-198.

Csanády, E.; Magoss, E. 2013. Mechanics of wood machining. Berlin: Springer-Verlag p.199.

Csanády, E.; Magoss, E.; Tolvaj, L. 2015. Quality of Machined Wood Surface. Berlin: SpringerVerlag p.257.

Csiha, Cs.; Gurau, L. 2011. Study on the influence of surface roughness on the adhesion of water based PVAC. In: Proceedings of International Conference "Wood Science and Engineering", Brasov, Romania, pp 411-419.

Dong, W.P.; Sullivan, P.J.; Stout, K. J. 1994. Comprehensive study of parameters for characterising three-dimensional surface topography: III: Parameters for characterising amplitude and some functional properties. Wear 178 (1-2): 29-43.

International Organization for Standardization. ISO. 2012. Geometrical product specifications (GPS) - Surface texture: Areal - Part 2: Terms, definitions and surface texture parameters ISO 251782:2012. <https://www.iso.org/standard/42785.html> (Accessed 08 Nov. 2018)

Fischer, R.; Schuster, C. 1993. Qualitäts entstehung spannend erzeugter Holzoberflächen. Institut für Holztechnologie. TU: Dresden, pp. 28-32.

GFMesstechnik. GFM. 2008. MikroCAD Optical 3D-measuring Instrument Software ODSCAD 6.0. Handbook

Gottlöber, C. 2014. Zerspanung von Holz und Holzwerkstoffen: Grundlagen - Systematik Modellierung - Prozessgestaltung. Fachbuchverlag Leipzig im Carl Hanser Verlag: München.

Gurau, L.; Irle, M. 2017. Surface Roughness Evaluation Methods for Wood Products: a Review. Curr Forestry Rep 3(2): 119-131.

Laina, R.; Sanz-Lobera, A.; Villasante A.; López-Espí, P.; Martínez-Rojas, J. A.; Alpuente, J.; Sánchez-Montero, R.; Vignote, S. 2017. Effect of the anatomical structure, wood properties and machining conditions on surface roughness of wood. Maderas-Cienc Tecnol 19(2): 203 - 212.

Malkoçoğlu, A. 2007. Machining properties and surface roughness of various wood species planed in different conditions. Building and Environment 42 (7): 2562-2567.

Molnár, Zs.; Magoss, E.; Fuchs, I.; Rosta, T. 2015. Einfluss von Bearbeitung und Befeuchtung auf die Oberflächentopologie von Vollholz. Holztechnologie 56(2): 10-19.

Molnár, Zs.; Magoss, E.; Fuchs, I.; Csiha, Cs. 2017. Stability of thermosmoothed and precision planed solid wood surfaces. $J$ Wood Product 76(1): 243-249.

Westkämper, E.; Riegel, A.; Kisselbach, A.; Schadoffsky, O. 1997. Gefügeschädigungen als Standzeitkriterium?. Teil I. Holz- und Kunststoffverarbeitung 32(9): 47-49.

Westkämper, E.; Riegel, A.; Kisselbach, A.; Schadoffsky, O. 1997. Gefügeschädigungen als Standzeitkriterium? Teil II. Holz- und Kunststoffverarbeitung 32(10):43-45.

Westkämper, E.; Riegel, A.; Kisselbach, A.; Schadoffsky, O. 1997. Gefügeschädigungen als Standzeitkriterium? Teil III. Holz- und Kunststoffverarbeitung 32(11): 80-82. 